\title{
Cycle-to-Cycle Fluctuations in a Spark Ignition Engine at Low Speed and Load
}

\author{
Sung Bin $\operatorname{Han}^{\dagger}$, Sung Il Hwang* \\ Department of Mechanical \& Automotive Engineering, Induk University, \\ *Department of Automotive Engineering, Suwon Science College \\ (Received 9 May 2012, Revised 10 June 2013, Accepted 10 June 2013)
}

\begin{abstract}
Cycle-to-cycle variation has long been recognized as limiting the range of operating conditions of spark ignition engines, in particular, under lean and highly diluted operation conditions. At a part load, some of the cycles tend to knock, while others may have incomplete combustion by the time the exhaust valve opens. An experimental study has been performed in order to evaluate the relative contribution of several relevant parameters on the cyclic variability in spark ignition engines. In general, the stability of engine operation is improved with fuel injector according to the optimal injection timing, but the stability of engine operation at idle is not improved compared with a practical gasoline engine. In this study, we investigated the relationship of the effect of operating conditions for the stability at low speed and load.
\end{abstract}

Key words : Air-fuel ratio, Engine speed, Cycle-to-cycle fluctuation, Variation, Standard deviation (STD), Hydrocarbon, Cylinder Pressure

\section{Introduction}

With the strengthening requirements of automobile pollutant legislation and continuous improvement of the thermal efficiency of internal combustion engines, more comprehensive and detailed research work has to be conducted. Spark ignition engines have the advantage of low thermal efficiency and the emissions of $\mathrm{HC}$ and $\mathrm{CO}$ still remain as the main problem. These can realize higher thermal efficiency owing to the higher pumping loss, higher heat loss and an decrease in the specific heat ratio, at the expense of the moderately higher $\mathrm{HC}$ and $\mathrm{CO}$ emissions resulting from the ineffectiveness of the existing catalyst [1].

Cycle-to-cycle combustion variations represent a problem to engine designer's for several reasons.

\footnotetext{
${ }^{\dagger}$ To whom corresponding should be addressed.

12 Choansan-ro, Nowon-gu, Seoul, 139-749, KOREA

Tel : 02-950-7545 E-mai : sungbinhan@induk.ac.kr
}

Since satisfying the customer is the primary goal of any automobile manufacturer, the consumer's perception of engine smoothness is an important concern. While the driver's perception of engine smoothness and noise may be influenced by many factors apart from the actual combustion variations, for instance, sound and vibration damping, engine mounting, drivetrain vibration-reducing combustion variations is necessary fr om the standpoints of drivability and customer satisfaction [2]. Cycle-to-cycle variation in spark ignition engines may be defined as the non-repeatabillity of the combustion process on a cycle-resolved basis. The causes of these variations in combustion have been discussed in depth in several reviews of the subject $[3,4]$.

The cyclic variation in the combustion process is generally accepted to be caused by variations in the mixture motion, in the amounts of air and fuel fed into the cylinder and their mixing, and in mixing with residual gases and exhaust gas recirculation, 
especially in the vicinity of the spark plug. The cyclic variability is usually attributed to the result of random fluctuations in equivalence ratio and flow field due to the turbulent nature of the flow in the cylinder. These spatial fluctuations that are also time-dependent, contribute to an imperfect mixing of the cylinder content, partial stratification, random convection of the spark kernel away from the electrodes, random heat transfer from the burning kernel to the spark electrodes, etc [5-7]

With the strengthening needs for automobile pollutant legislation and continuous improvement of thermal efficiency of internal combustion engines, more comprehensive and new research work needed to be carried out. Up until now, many systematic studies have revealed the mechanism and control strategies on SI cycle-by-cycle variations. However, relatively little work has been reported on cycle-by-cycle variations and the stability of homogeneous charge compression ignition combustion [8].

During the last decade, extensive researches have enriched our knowledge in this subject. It is the purpose of the present paper to review and discuss the different indicators of cyclic variability used in the literature, to evaluate the relative contribution of the various factors by means of a literature survey, and to designate the best operation conditions to minimize the cycle-by-cycle variations [9].

Cyclic variability has long been recognized as limiting the range of operating conditions os spark

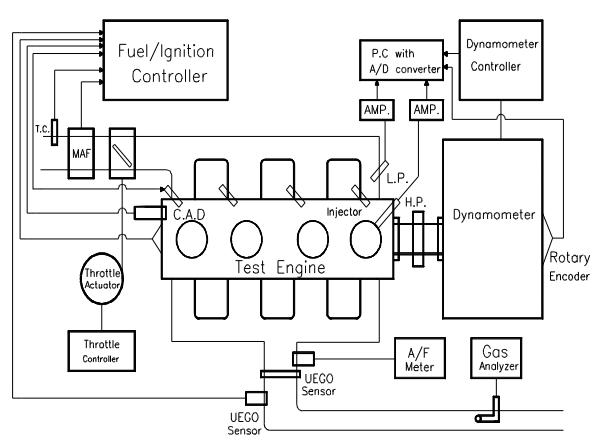

Fig. 1. Schematic diagram of experimental apparatus. ignition engines, in particular, under lean and highly diluted operation conditions. The cyclic combustion variations can be characterized by the pressure related parameters, combustion related parameters, and flame front related parameters. Although the pressure measurement is still one of the most useful tools for analyzing the cyclic combustion variation, the development of advanced techniques for the in-cylinder measurement of the flame initiation and propagation can lead to deeper understanding of the origin and impacts of cycle-by-cycle variation $[10$, $11]$.

The cyclic variability results also in high levels of variation in the engine speed that is interpreted as poor driveability. At full load, some of the cycles tend to knock, while some others may not have complete combustion by the time the exhaust valve opens.

This research focuses on the engine cycle-to-cycle variations under the idle operating condition. At idle the environment is unfavorable to combustion because the charge is significantly diluted by residual gas. Also, pressure fluctuations at idle are particularly objectionable to the driver because of the low frequency excitation of mechanical vibrations of the various panels in the passenger compartment. The objective of this research is to identify and quantify the sources of cycle-to-cycle. In this research, author studied the influence of electronically controlled fuel injection in a gasoline engine on combustion stability with fuel injection time and air-fuel ratio.

\section{Experimental Set-up and Procedures}

The specification of the engine is shown in Table 1. An engine control system (IC 5460, Intelligent Controls) was used to control the fuel injection timing and spark timing. An air-fuel ratio measurement system (UEGO Sensor, Horiba 110) was used to measure the air-fuel ratio. The fuel injection timing, air-fuel ratio, spark timing, and dwell angle were the experimental operating 
Table 1. Specification of engine used.

\begin{tabular}{c|c}
\hline Engine type & $\begin{array}{c}\text { Water cooling, } \\
\text { Double overhead cam-shaft }\end{array}$ \\
\hline \hline Total displacement & $1998.4 \mathrm{~cm}^{3}$ \\
\hline Bore $\times$ stroke & $8.6 \times 8.6 \mathrm{~cm}$ \\
\hline Number of cylinder & 4 \\
\hline Compression ratio & 9.5 \\
\hline Intake valve & Open $13^{\circ} \mathrm{BTDC}$ \\
Close $55^{\circ} \mathrm{ABDC}$
\end{tabular}

variables at idle.

The engine speed at idle is fixed at $800 \mathrm{rpm}$ without the automatic idling control device. The cooling water temperature is fixed at $80^{\circ} \mathrm{C}$. To study the influence on idle with fuel injection timing variables, spark timing is fixed at 10 BTDC and the fuel injection timing is changed to 180,90 and $0^{\circ} \mathrm{BTDC}$, and $45,90,135$ and $180^{\circ} \mathrm{ATDC}$. To evaluate the variations of engine speed, the mean value of maximum engine speed and minimum engine speed during 60 seconds were measured. A piezo-electric pressure transducer, Kistler 6061B, was mounted in the cylinder head to measure the cylinder pressure. The average cylinder pressure diagram of the 100 consecutive cycles was used to evaluate the stability at idle. A absolute pressure sensor (Kistler 4045A2) was used to measure the inlet pressure.

In this paper, to study the influence of spark timing variables at idle, the spark timing was

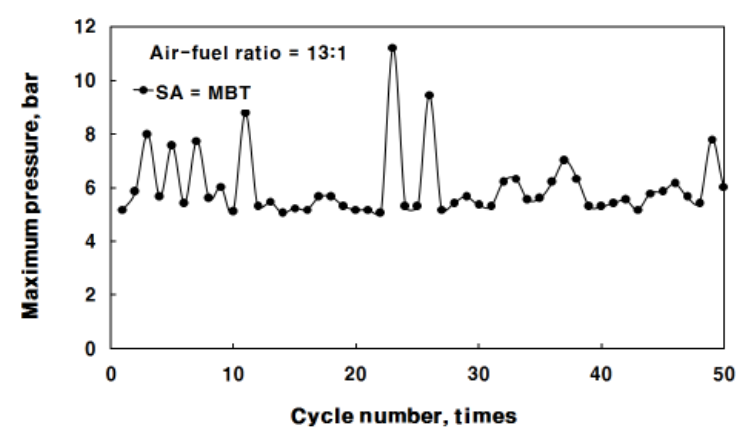

Fig. 2. Maximum cylinder pressure vs. cycle number at air-fuel ratio 13:1.
MBT(minimum spark advance for the best torque). And the air-fuel ratio was changed to $13: 1,14.7: 1$ and $16: 1$.

\section{Results and Discussion}

To investigate the significance of variations in fuel injection timing on engine speed variability, we used a constant spark timing MBT(minimum spark advance for the best torque). The air-fuel ratio was changed to $13: 1,14.7: 1$ and $16: 1$.

Figure 2 shows the maximum cylinder pressure versus cycle number at air-fuel ratio 13:1 and MBT. Figure 3 shows the maximum cylinder pressure versus cycle number at air-fuel ratio 14.7:1 and MBT. Figure 4 shows the maximum cylinder pressure versus cycle number at air-fuel ratio 16:1 and MBT. As the air-fuel ratio is richer according to the change of injection timing, the engine speed variations increase.

Figure 5 shows the effect of injection timing on the engine speed variation. It is represented by the mean value of the maximum and minimum engine speed at idle during each the fuel injection period for 60 seconds. In this figure, the injection timing for the most stable engine speed for air-fuel ratio is before the inlet process $90^{\circ}$ BTDC. The engine speed variations of maximum and minimum at $90^{\circ}$ BTDC in air-fuel ratio each are about $4.3 \%$. From this figure, the injection timing in the period just before the inlet valve opening helps the

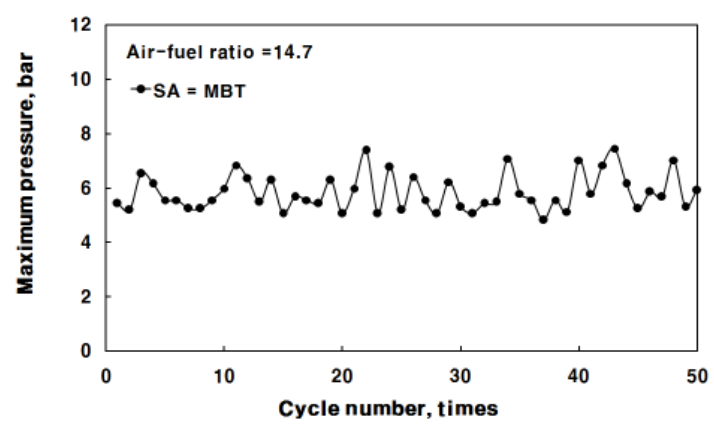

Fig. 3. Dynamic charge-discharge current of $90 \mathrm{Ah}$ lead-acid battery 


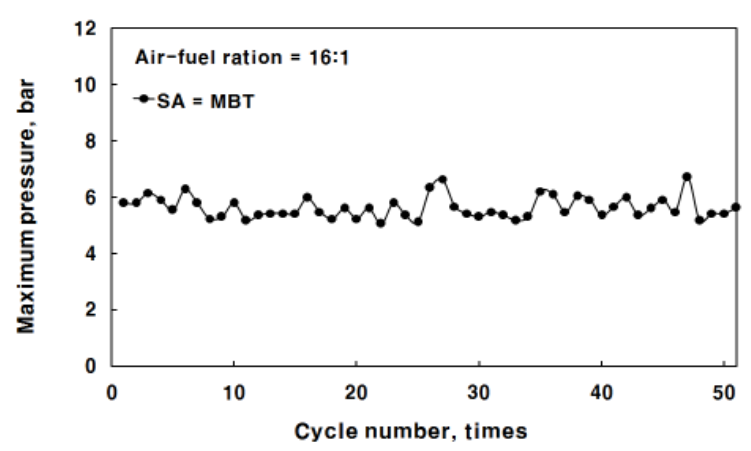

Fig. 4. Maximum cylinder pressure vs. cycle number at air-fuel ratio $16: 1$.

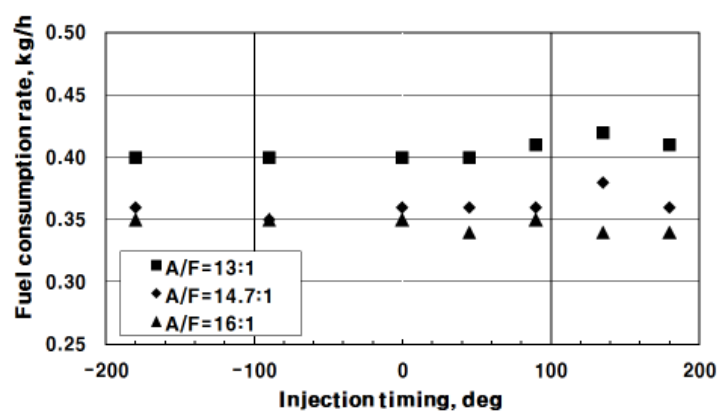

Fig. 6. Fuel consumption rate vs. injection timing.

stability at idle.

In addition, fuel injection timing during the inlet process or after inlet valve closed may increase the engine speed variations, and specifically the engine speed variation for injection in the latter portion of inlet process at air-fuel ratio 16:1 increases remarkably. This means that the engine speed variation increases with injection timing variation as the air-fuel ratio increases.

Figure 6 shows the effect of injection timing on the fuel consumption rate at idle. The fuel consumption rates are about $0.35 \mathrm{~kg} / \mathrm{h}$ and $0.42 \mathrm{~kg} / \mathrm{h}$ for air-fuel ratio $16: 1$ and $13: 1$, respectively. The fuel consumption rate with injection timing variables at each air-fuel ratio have the same value generally, but they increase somewhat if the fuel injecting timing is after inlet process. The fuel injection timing after inlet process at idle is disadvantageous in terms of fuel economy. It is

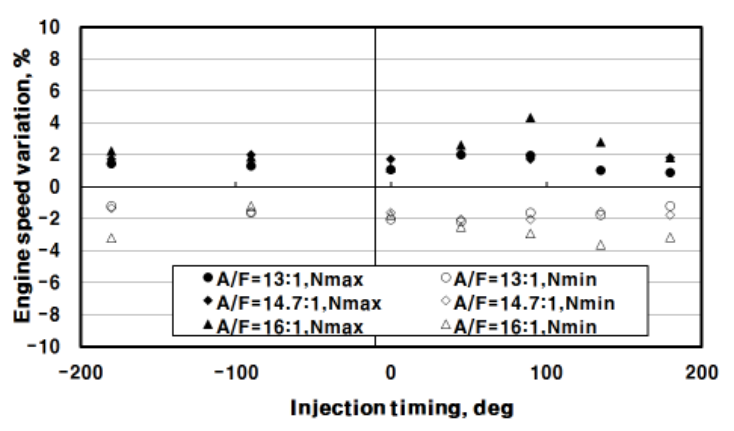

Fig. 5. Engine speed variation vs. injection timing.

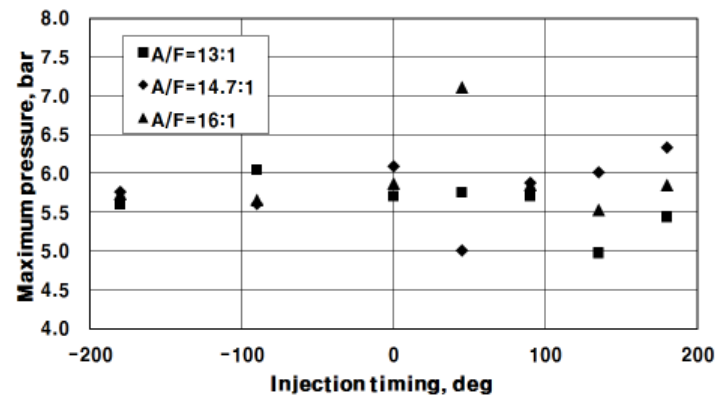

Fig. 7. Maximum cylinder pressure vs. injection timing.

believed that for the fuel injection timing after inlet process begins does not leave enough time for the formation of a homogeneous mixture, and some mixture left in the inlet runner causes combustion variability.

Figure 7 shows the maximum cylinder pressure versus injection timing. The maximum cylinder pressure values remain essentially the same at about 6 bar for each air-fuel ratio. The maximum cylinder pressure with fuel injection timing are almost the same values. But for the fuel injection timing in the latter period of the inlet process, despite much injection in the latter period of inlet process as shown in Fig.6, the maximum cylinder pressure values are somewhat unsteady as shown in Fig.7. This means that the fuel consumption rates are increased and unsteadied at idle by the fuel injection timing in the latter period of inlet process, so it is better to avoid fuel injection in the latter 


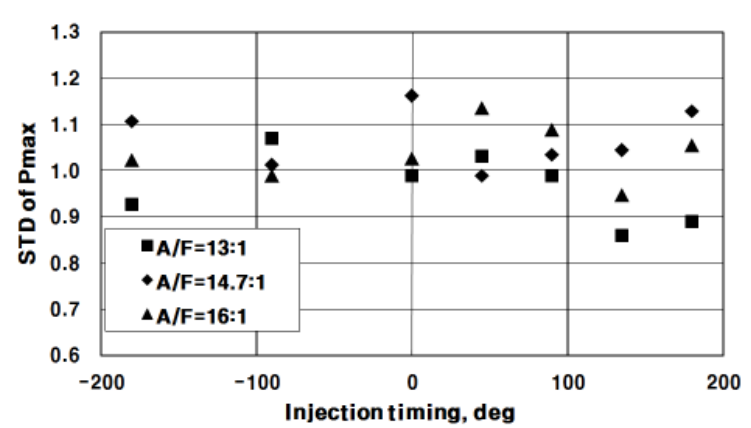

Fig. 8. Standard deviation of maximum cylinder pressure vs. injection timing

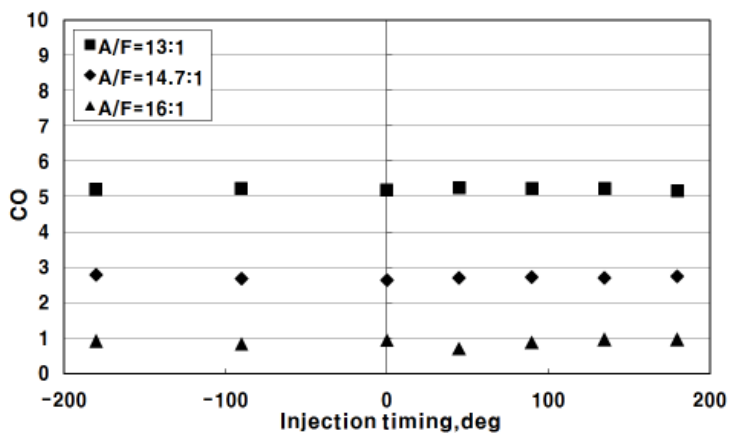

Fig. 10. Carbon monoxide vs. injection timing

period of inlet process for the stability at idle.

Figure 8 shows the standard deviation of maximum pressure in the cylinder with fuel injection timing. Standard deviation in the cylinder pressure is determined from a sample of 100 cycles. In this figure, the standard deviation of maximum pressure in cylinder at idle is about $1 \%$, and it decreases somewhat as the fuel injection timing is changed to later during the inlet process. The standard deviation of maximum pressure in cylinder with injection timing is from 0.86 to 1.16 on the whole. For the lowest standard deviation of the maximum pressure the best timing is about $135^{\circ} \mathrm{ATDC}$.

Figure 9 shows the engine out hydrocarbon concentration versus fuel injection timing. The hydrocarbon concentration at idle is determined by air-fuel ratio. Hydrocarbon emissions for air-fuel ratio $13: 1$ and 16:1 are maximum $550 \mathrm{ppm}$ and 340

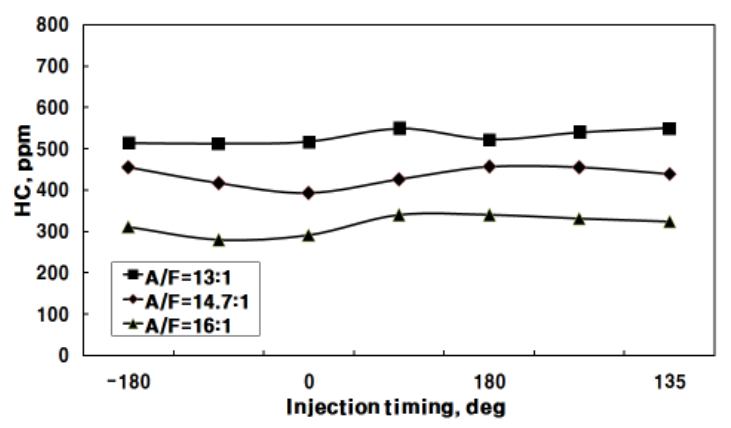

Fig. 9. Hydrocarbon vs. injection timing.

ppm at $90^{\circ} \mathrm{ATDC}$, respectively. When the fuel injection is on the latter period of the inlet process, hydrocarbon emissions increase somewhat with the increase of fuel supplied. The engine out hydrocarbon versus the injection timing is shown in Fig. 9. The hydrocarbon concentration increases as the air-fuel ratio is richer according to the change of injection timing. As the injection timing is advanced, Hydrocarbon emissions decrease rapidly very little. The change temperature at the end of expansion/beginning of exhaust is higher with retard timing, leading to more post-flame hydrocarbon oxidation and lower hydrocarbon emissions. Generally hydrocarbon emissions increase at idle or low load, to decrease hydrocarbon emissions at low speed, it is advantageous to retard the injection timing.

In the injection timing from -200 to +200 angle degree for air-fuel ratio 13:1, carbon monoxide concentration is highest. In this case, the carbon monoxide emissions are increased as the air-fuel ratio is richer according to the change of injection timing as shown in Fig.10.

\section{Conclusions}

1) The injection timing for the most stable engine speed for air-fuel ratio is before the inlet process $90^{\circ} \mathrm{BTDC}$. The engine speed variations of maximum and minimum at $90^{\circ} \mathrm{BTDC}$ in air-fuel ratio each are about $4.3 \%$. 
2) The standard deviation of maximum pressure in cylinder with injection timing is from 0.86 to 1.16 on the whole. For the lowest standard deviation of the maximum pressure the best timing is about $135^{\circ} \mathrm{ATDC}$.

3) For air-fuel ratio $13: 1$ to $16: 1$ at idle, the maximum pressure in cylinder with air-fuel ratio and fuel injection timing is almost constant, and the maximum pressure variation in cylinder with injection timing at idle is about $1 \%$. Hydrocarbon emissions at idle are in proportion to fuel injection quantities.

\section{References}

1. Huang, Z., Shiga, S., Ueda, T., Nakamura, H., Ishima, T., Obokata, T., Tsue, M. and Kono, M., 2003, Study of cycle-by-cycle variations of natural gas direct injection combustion using a rapid compression machine. Proc. Inst. Mech. Eng., Part D, J. Automobile Engineering 217, 53-61.

2. Hinze, P. C, 1997, Cycle-to-cycle combustion variations in a spark-ignition engine operating at idle, MIT Ph.D. dissertation.

3. Xingeal, L., Libin, J., Junjun, M. and Zhen. H., 2007, Experimental study on the cycle-by-cycle variations of homogeneous charge compression ignition combustion using primary reference fuels and their mixtures. Proc. Inst. Mech. Eng., Part D, J. Automobile Engineering 221,859-866.

4. Shen, H., Hinze, P. C. and Heywood, J. B., 1996, A study of cycle-to-cycle variations in SI engines using a modified quasi-dimensional model, SAE Paper No.961187.

5. Salvat, O. P., Cheng, A. S., Cheng, W. K. and Heywood, J. B., 1994, Flame shape determination using an optical-fiber spark plug and a head-gasket ionization probe," SAE Paper 941987, 1994.

6. Lee, K. H. and Foster, D. E., 1995, Cycle-by-cycle variations in combustion and mixture concentration in the vicinity of spark plug gap, SAE Paper 950814, 1995.

7. Shen, H., Hinze, P. C. and Heywood, J. B., 1996, A study of cycle-to-cycle variations in SI engines using a modified quasi-dimensional model," SAE Paper 961187.

8. Xingcai, L., Libin J., Junjun M. and Zhen H., 2007, Experimental study on the cycle-by-cycle variations of homogeneous charge compression ignition combustion using primary reference fuels and their mixtures, J. Automobile Engineering 221, 859-866.

9. Heywood, J. B., 1988, Internal Combustion Engine Fundamentals, McGraw-Hill Book Co.

10. Huang, Z., Shiga, S., Ueda, T., Nakamura, H., Ishima, T., Obokata, T., Tsue, M. and Kono, M., 2003, Study of cycle-by-cycle variations of natural gas direct injection combustion using a rapid compression machine. Proc. Inst. Mech. Eng., Part D, J. Automobile Engineering, 217, 53-61.

11. Rousseau, S., Lemoult, B. and Tazerout, M, 1999, Combustion characterization of natural gas in a lean burn spark-ignition engine, Proc. Inst. Mech. Eng., Part D, J. Automobile Engineering, 213, 481-489. 